\title{
Exploration and construction of fiscal and taxation policies to promote the development of marine circular economy
}

\author{
Guo Lanhua, Li Jinyan \\ Qingdao Institute of Technology \\ Correspondence Author: Li Guangqin
}

Keywords: marine circular economy, fiscal and taxation policies, exploration and construction

\begin{abstract}
With the rapid development of China's economy, the green economy is a necessary part of the sustainable development of marine economy.To a certain extent, the development of the marine economy can gradually ease the pressure of the economic development of the land. The ocean as a new area of economic development, in the wake of the development will have more and more important role, whether domestic or foreign, and utilization of marine resources and become a new economic development in the direction of the major trend.How to promote the development of marine circular economy has become the focus of attention of the world.In recent years, the development of marine circular economy in our country has carried on many directions to explore and try. In recent years, with the gradual development of the marine economy, the problems exposed are endless, damage to the marine ecological environment, promote the development of marine circular economy is imperative. Among them, the core of the most important in the development of the marine circular economy in the process of fiscal policy exploration and construction. The framework of fiscal and tax policy is related to social equity, social resource distribution, national macro-control and so on. This paper mainly from the concept of marine circular economy theory, the defects of China's existing fiscal and taxation policies of the marine circular economy, how to promote the development of marine circular economy and the feasibility of the construction of fiscal policy. In order to better promote the development of marine circular economy in our country to put forward some useful views.

Marine economy can be said to be a hot vocabulary in recent years, and the existing methods of the development of marine economy, greatly harm the marine environment, to a large extent, the impact of the development of the marine economy. The development of the marine circular economy is to put forward a feasible solution to the existing dilemma, optimize the allocation of resources, reduce the loss of resources, protect the marine environment. From an economic point of view, to promote the development of circular economy, is to explore the construction of a good fiscal policy, in order to solve the problems in the sustainable development of marine circular economy to provide a feasible solution. To optimize the structure of the industry, to achieve the goal of resource allocation, and to increase the development of the enterprise, is the development needs of China's marine economy and fiscal and taxation policies to meet the existing marine circular economy. Innovative new tax system, improve the efficiency of development has become the only way for China to promote the development of marine circular economy.
\end{abstract}

\section{The concept of marine circular economy}

\subsection{Concept definition}

The sustainability of marine economy is the core content of marine circular economy development strategy, in the rational use of earth's resources based on, live in harmony with nature, reduce damage to the natural resources of the ecological system, balance protection diversity and productivity development demand relationship, efficient solution of marine resources limited supply and human on the contradiction between the demand for marine resources. These problems is the problem of the development of marine circular economy never. On the one hand, the sustainable development of the marine economy is also reflected in the green economic development model of the marine economy. 
Marine green economy, marine circular economy is in the protection of the environment, respect under the premise of the ocean, "recycling", the human use the seesaw of marine resources and the protection of the marine to find a balance, to seek a long-term coexistence state, to achieve a win-win situation. The formation of "production - consumption - decomposition of the industrial structure and establish a whole symbiotic seek common system of relations, improve the utilization rate of resources, to achieve a circular economy development model, to reduce the loss of resources, marine resources integration and strive to minimum the economic development cost to achieve the maximization of the marine environmental protection benefit and ocean circulation economic development benefits.

\subsection{Advantages of the marine circular economy \\ 1.2.1 Optimize the industrial structure}

Taking a review of the existing structure of marine industry in China, it is obvious that our country is still the traditional inefficient industrial structure. Still with the loss of natural resources for economic development, industry growth, the basis of the company's business. The marine circular economy can coordinate the allocation of resources to a great extent, promote the harmonious development of the region, improve the efficiency of development and speed up the pace of transformation. More importantly, the marine circular economy to optimize the industrial structure, improve the efficiency of.

\subsubsection{Realize the sustainable development}

Marine circular economy follow the principle of protecting the environment above, the realization of the sustainable development of the marine economy of our country, reduce the human damage to the natural environment, causes the human and the nature in better harmony, increase the effectiveness of at the same time, but also increases the possibility of coexistence of long-term development, "emission reduction, reuse, recycle" and improve the resource utilization rate, reduce the number of unnecessary loss and waste.

\section{Defects in the existing fiscal and taxation policies of the marine economy}

In recent years along with our country to the marine circular economy highly value, our country to the marine circular economy's finance and tax system's discussion also gradually enriched. In 12th Five-Year, China clearly put forward the development strategy of marine economy, and put forward the development of marine economy. China's marine economic and fiscal policy is still subject to some constraints, there are some defects.

\subsection{No system of marine economic and fiscal policy}

On China's current economic and fiscal policy, and not a complete system of marine economy related fiscal and tax policies. And environmental protection on the value-added tax, resource tax, consumption tax, etc., the relevant provisions are not specific, the lack of overall coordination, on marine economy of fiscal policy are scattered in a variety of other categories of taxes, and there is no system integration, such as some salt salt flats, Marina Bay will be exempted from urban land use tax policy, cultivating boat of travel tax exemption policy, fishery production with and so on the related policy. And some of the taxes and even in the development of circular economy damage, resulting in repeated tax increases, increasing the pressure on the company's development;circular economy mostly high-tech and capital intensive equipment investment as the main characteristics of the organic composition of capital circulation enterprises is relatively high, a large amount of equipment purchase costs, the cost of the product high proportion of equipment, income tax shall be deducted in the cost of products, due to the subsequent production link of double taxation. This is not conducive to the development of marine circular economy and the formation of green economic benefits.

\subsection{Financial investment is too small}

In some areas of China's marine resources are exhausted day by day, marine economic income is also a lack of a good is conducive to the development of external environment and investment, marine and a large number of animals are killed, water quality, marine ecological environment is seriously polluted. Although China's rapid economic development, the growth rate of fiscal revenue 
to speed up, for the development of China's green marine circular economy, lay a solid foundation to provide a strong support. But in the "85", "95", "15" and "Eleventh Five Year" during the environmental protection investment respectively accounted for only GDP over the same period of $0.74 \%, 0.88 \%$ and $0.99 \%$ and $1.35 \%$, from data analysis, can be obtained, in China on environmental projects, funding is not complete, and other areas of finance investment amount gap directly leads to reduce some of the sustainability of the project feasibility, does not meet the modern economic development trend. In the formulation of fiscal policy, the lack of clear targeted, not fully consider the characteristics of the marine circular economy, so that the development of the marine economy has been constrained, the scale has been affected.

\subsection{Financial subsidy policy is not perfect}

The active implementation of the fiscal subsidy policy is an important link in the development of marine circular economy. The government can through some has for the specific preferential policies, to the enterprise for some of the benefits of price subsidies, fiscal subsidies, subsidies to loss making enterprises such as, the enhancement enterprise go a sustainable road of confidence to the enterprise green a strong support. In the reality of our country's marine circular economy development process, flexible use of financial subsidy policy in a certain extent can greatly enhance consumer purchase plan, to stimulate the enthusiasm of producers of the production, and finally to promote consumer products to promote economic development. China's existing financial subsidies mainly direction in marine infrastructure and environmental protection in the field, but to promote the comprehensive utilization of resources from pollution control to subsidies and not enough, subsidy way is not reasonable, on marine enterprise motivation and support effect is not obvious, resulting in the development of some enterprises enthusiasm and initiative is not high, can not effectively adapt to the strategy of sustainable development of marine economy. It not only causes the wasteful phenomenon, reduce the rate of resource utilization, but also hinder the overall development of China's marine circular economy.

\section{To promote the development of China's marine circular economy and the feasibility of the construction of fiscal policy.}

\subsection{Establish environmental protection tax system}

In consideration of the actual development of China's marine circular economy, the appropriate reasonable expansion of the scope of tax revenue, the establishment of environmental protection tax system. The indicators of the marine environment are reasonably incorporated into the preferential policies of tax. Not to say that the marine ecological environmental aspects of the tax. Establish an environmental protection tax system, the part of the reasonable use of the protection of the ecological environment of special projects to increase environmental protection part of the scientific research funding, to promote the development of science and technology in China's environmental protection.

\subsection{Perfect our country's financial subsidy policy}

Increase China's policy on financial subsidy the rationality and the feasibility in practice, according to the goal of China's marine circular economy development and the inherent requirements, in combination with the status quo of China's marine circular economy based on the formulated our country's financial subsidy policy, improve the financial subsidies subsidies to in our country. To establish a perfect financial subsidy policy, after taking into account the marine infrastructure after the completion is the actual situation of idle, financial subsidies construction facilities by the early to late facilities maintenance transformation, improve the utilization rate of funds, improve the actual effect of financial subsidies.

\subsection{To strengthen the government procurement efforts}

In the face of difficulties in the development of marine economy, the government to enhance the procurement efforts to solve the problems faced by these enterprises. In new high-tech marine products to enter the market, can effectively regulate market demand, the overall market demand remained in a steady state, with the marine high technology to a promote marine market, eliminate trade barriers. Once the government strengthen the high-tech product procurement efforts will for 
the industry of the marine economy injection new vitality, play the exemplary role of government consumption, improve the economic effect of industry, promote the development of marine economy, enhance competitiveness.

\section{Conclusion}

To promote the finance and taxation policy of China's marine circular economy development of exploration and construction is the inevitable requirement of the economic development of our country, but in the past few decades, without control of marine development has destroyed the renewability of marine resources, which restricts the benign development of the marine economy of our country. The introduction of the fiscal and taxation policies of the marine circular economy is conducive to promoting the further development of marine circular economy, an important way to solve the marine pollution, but also a major step in the marine economy in china. By means of fiscal and taxation, the government makes a reasonable adjustment to the external environment, and the pressure brought by artificial relief reflects the fairness of the process of economic development.

\section{Reference}

[1] Shandong Peninsula Blue Economic Zone of the marine industry development status and Countermeasures of [J]. commercial culture (the second half), 2012 (2).

[2] Zhou Shulian and Liu Jiejiao, from the transformation of economic growth mode to the transformation of economic development mode [N]. Guangming Daily, 2007-12-11.

[3] Chen equality. Study on the mechanism of fiscal and taxation policies for the development of China's marine economy [J]. marine economy, 2012 (1).

[4] Xu Congchun, Wang Xiaohui, Li Shuangjian et al. Analysis on the development and management of marine circular economy [J]. ocean development and management, 2006 (3): 67 70 